\title{
Fetus in Fetu: A rare presentation in an adult female
}

\author{
S. K. Jain, Prashant Gill, Vandana Jain, K.M. Garg \\ Department of General Surgery, Mahatma Gandhi medical college and hospital, Jaipur, India
}

\begin{abstract}
A rare case of Fetus in Fetu (FIF), in a 28 years old female presented as retroperitoneal mass abdomen. Computed tomography scan revealed multiple bones, fatty and cystic components. The mass was successfully excised. After removal of the specimen, the macroscopic appearance, X-ray and histopathologic examination confirmed it as fetus in fetu. Fetus in Fetu should be kept as differential diagnosis of retroperitoneal mass lesions.
\end{abstract}

Keyword: Fetus in Fetu(FIF), Mature Teratoma, Retroperitoneal Mass

\section{Introduction}

Fetus in Fetu (FIF) is a rare condition associated with abnormal embryogenesis in a diamniotic, monochorionic pregnancy, where in a vertebrate fetus is enclosed within the body of another normally developing fetus ${ }^{[1]}$. It is a rare anomaly which can be differentiated from a retroperitoneal teratoma by the presence of a calcified vertebral axis and limb buds within the mass. FIF is a malformed parasitic twin included in host twin due to unequal division of totipotent cells of a blastocyst, resulting in the inclusion of small cellular mass in a more mature embryo thus forming a monozygotic, diamniotic twin pregnancy. It is a rare condition with $89 \%$ cases presenting in neonate and children, before the age of 18 months and only few cases have been reported after the age of 15 years ${ }^{[2]}$. Herein we report one such case in a 28 years old female.

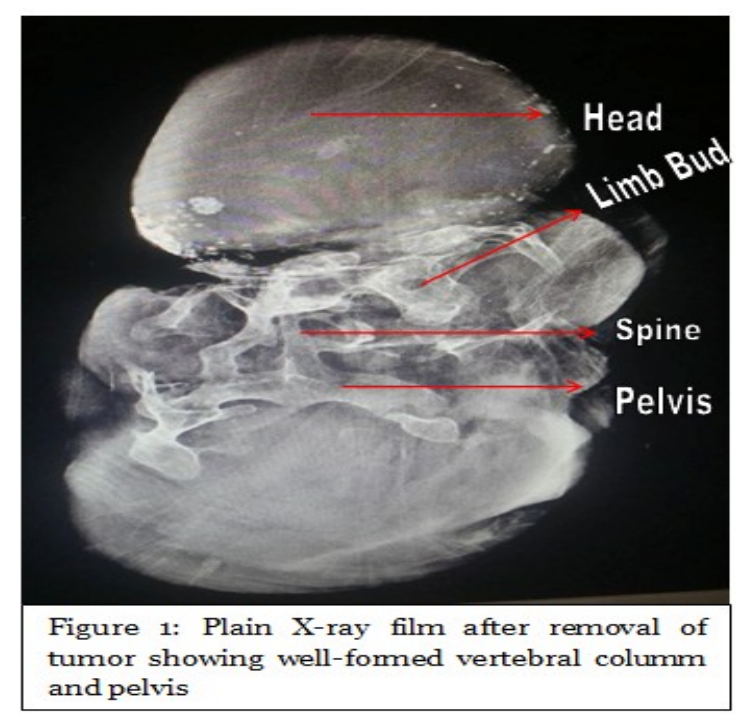

\section{Case Report}

A 28 year old female was admitted with complaints of lump left side of abdomen from last 8 years and pain in abdomen and constipation from 4 months. Patient noticed a lump in left side of abdomen just after she got pregnant 8 years back. Patient delivered a normal healthy baby, but the lump was still present and increased in size gradually upto the present size. On examination a $18 \mathrm{~cm} \times 12 \mathrm{~cm}$ lump was palpable in left hypochondrium upto lumbar region and reaching upto midline, which was firm to hard in consistency, smooth, non tender. No family history of twin pregnancy or teratoma. Abdominal Ultrasound showed a solid-cystic mass with mixed echogenicity. Computed Tomography scan of the abdomen revealed a large heterogeneous dense lesion consisting of multiple bones, fatty and cystic components in the retroperitoneal region superior to the left kidney. Size of lesion was 123 x 116 x $228 \mathrm{~mm}$ with probable diagnosis of Fetus in Fetu or Retroperitoneal Germs Cell Tumor. The Alpha Fetoprotein levels were normal. 


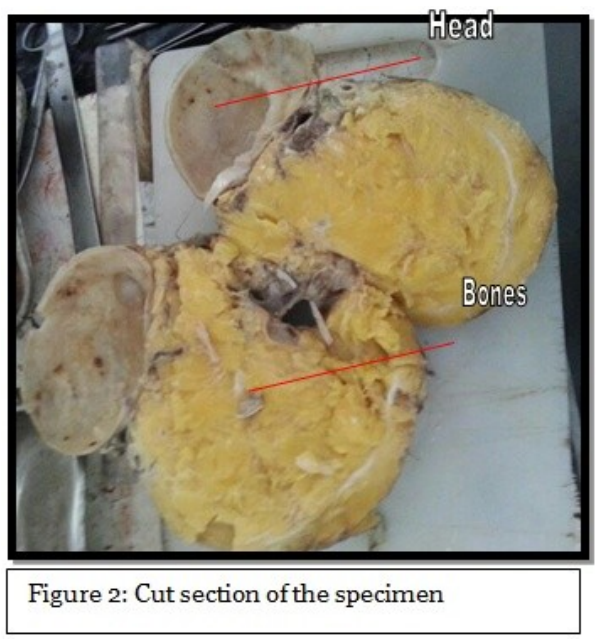

On exploration, there was a well encapsulated mass occupying the left side of the retroperitoneal space, extending from the left hypochondrium to left iliac region and upto the midline, pushing body and tail of pancreas anteriorly (at the middle of tumor) kidney was pushed to left iliac fossa. With meticulous dissection the descending colon was mobilized medially, the pancreas pushed upward towards the splenic flexure, left kidney with vascular pedicle downwards, then the mass was removed. On examination the tumour content consisted of one litre of yellow coloured fluid and incomplete anencephalic fetus weighing 5.5kilograms. The rest of solid area composed of fibro-fatty muscular tissue, cartilage, marrow element(Bone marrow) and cyst lined by benign epithelial cells with focal areas of calcification. Patient tolerated the procedure well and was healthy when seen at 3 months follow-up.

\section{Discussion}

Fetus in fetu is a rare condition occurring once in 500,000 deliveries ${ }^{[3]}$. It is a parasitic monozygotic tumor predominantly found in neonates and children. Fetus in fetu presents as a lump in the abdomen (70\%) and the retroperitoneal space is the commonest site $(80 \%)$. Other rare sites include sacro-coccygeal region, intracranial, thorax, pelvis and the scrotum. Late presentation at the age of 28 years in the present case may be due to a dormant fetus which started growing under the influence of a host pregnancy. Computed Tomography scan is the most reliable diagnostic imaging showing fat collection around the central bony structures ${ }^{[4]}$. However, rarity of presentation at a later age may lead to the pre-operative misdiagnosis as Retroperitoneal Teratoma.

Single parasitic fetus is the commonest presentation (88\%), multiple fetus ranging from 2-5 have also been reported. The present fetal size was $23 \mathrm{~cm} \times 12 \mathrm{~cm}$, the reported size varies between $4 \mathrm{~cm}$ and $24 \mathrm{~cm}$. The fetal weight varies between $1.2 \mathrm{~kg}$ and $1.8 \mathrm{~kg}$, and it was $5.5 \mathrm{~kg}$ in this present case. Visualization of the vertebral column and limbs on imaging, gross, and histo-pathological examination confirms the diagnosis. This fulfills the "Willis criteria" which stresses much in turn is an advanced primitive streak stage ${ }^{[5]}$.

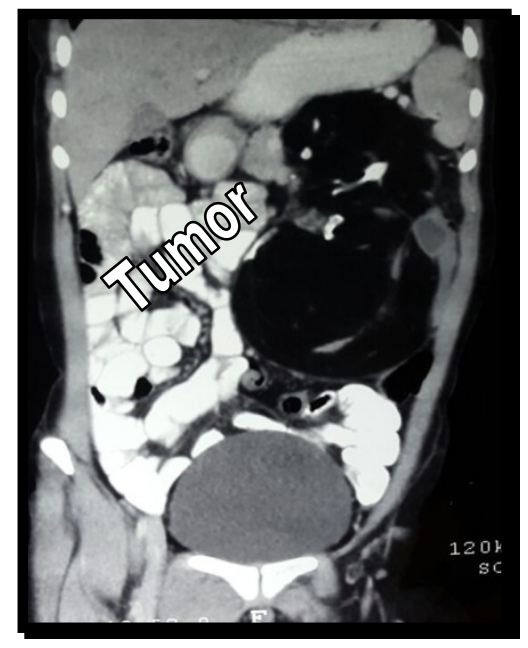

Figure 3: Computed Tomography of abdomen illustrating Fetus in Fetu 
The majority of fetus in fetu present in early years of life and only a few cases have been reported in patients over the age of 15 years. There is a controversy whether a fetus in fetu is the distinct entity or a highly organized teratoma. Some authors claim that fetus in fetu is a well differentiated highly organized teratoma, while others claim it to be a different pathological entity ${ }^{[6]}$. Fetus in fetu occurs in the upper retroperitoneum whereas teratomas occur in the lower retroperitoneum, pelvis, ovary and sacro-coocygeal regions ${ }^{[7]}$. Malignant transformation is rare in fetus in fetu and only one case has been reported in literature ${ }^{[8]}$.

The presence of vertebral column is an important diagnostic criterion which suggests the development of a notochord which in turn is an advanced primitive streak stage. A non calcified vertebral column invisible on radiograph or on Computed Tomographyscan or its total absence $(9 \%)$ does not exclude diagnosis of fetus in fetu $^{[9]}$. However, the presence of a bony vertebral axis with appropriate limb arrangement on gross is an important diagnostic feature which was observed in the studied case, thus confirming the diagnosis of fetus in fetu $^{[10]}$. Other differentiating features include normal levels of Alfa-fetu protein in fetus in fetu. A new diagnostic modality (molecular analysis) is using an informative genetic marker for uniparentalisodisomy of chromosomes 14 and 15, if it shows no genetic difference between the host and the fetiform mass, then it is diagnostic of fetus in fetu ${ }^{[11]}$.

Fetus in fetu derives its blood supply from the rich vascular plexus around the cyst wall. Vascular pedicle is rare and usually observed in large growing masses with delayed presentation ${ }^{[12]}$. The FIF complex is characteristically composed of a fibrous membrane (equivalent to the chorioamniotic complex) that contains some fluids (equivalent to the amniotic fluid) and a fetus suspended by a cord or pedicle. In the uterus, the growth of an FIF initially parallels that of its twin but stops abruptly because of either the vascular dominance of the host twin or an inherent defect in the parasitic twin ${ }^{[12]}$. FIF is mostly anencephalic, but in almost all cases its vertebral column and limbs are present (91\% and $82.5 \%$, respectively), although the most common site is the retroperitoneum. FIF has been reported at various sites right from the cranial cavity to the scrotal sac ${ }^{[12]}$. Different organs can be seen in FIF whichinclude the vertebral column (91\%), limbs (82.5\%), central nervous system $(55.8 \%)$, gastrointestinal tract $(45 \%)$, vessels $(40 \%)$, and genitourinary tract $(26.5 \%)^{[13,14]}$. Even without performing an operation to remove the parasitic twin the existence of the condition can be diagnosed through ultrasonography, plain X-ray and a Computed Tomography scan of the host's abdomen. The treatment of choice for a case of Fetus In Fetu is surgical excision.

\section{Conclusion}

Fetus in fetu is commonly seen in childhood. Presentation at the age of 28years is very rare. Fetus in fetu should always be kept as differential diagnosis of retro peritoneal mass lesion in adults and its surgical removal is the treatment of choice.

\section{References}

[1]. Hoeffel C C , Nguyen KQ, Phan HT, Truong NH, Nguyen TS, Tran TT, Fornes P:Fetus in fetu: a case report and literature review.Pediatrics2000, 105:1335-1344.

[2]. Massed MG, Kory L, Beneditti E, Ghorl RD, Geha AS, Abcarian H. Dysphagia caused by a fetus in fetu in a 29 year old man. Am.Thorac. Surg, 2001; 71(45):1338-1341.

[3]. Grant P, Pearn JH. Foetus in foetu, Med J. Aust1969; 1:1016 -1020.

[4]. Nagar A, Raut AA, Narlawar RS. Foetus in Fetu. J Postgrad Med 2002; 48:133-134.

[5]. Willis RA. The borderland of embryology and pathology 2nd ed. Washington DC: Butterworth, 1962; 442-462.

[6]. Potter EL. Pathology of the fetus and the newborn. In: Potter EL, ed. Pathology of the fetus and the newborn. 2nd ed. Chicago, Ill: Year Book, 1961; 183-187.

[7]. De Lagaurie P, de Napoli CS, Stempfli N, Truong QD, Vuillard E, Ferkadji L, et al. Highly differenciated teratoma and fetus in fetu: a single pathology? J PediatricSurgery1997; 32:115 -116

[8]. Hopkin KL, Dickson PK, Ball TI, Ricketts RR, O'Shea PA, Abramovosky CR. Fetus in fetu with malignant recurrence. J PediatricSurgery1997; 32:1476- 1479.

[9]. Moorthy K, Rao PP, Deshpande AA, Thakur RK, Supe AN. Fetus in fetu or a retroperitoneal teratoma--a controversy revisited. A case report and review of literature.Indian J Cancer. 1997; 34(4):179-181.

[10]. Hsiao YC, Chen CC, Shih TY, Shih HS, Chen W, Wu NK. Fetus in fetu: report of a single case. Zhonghua Min Guo Xiao ErKe Yi XueHuiZaZhi. 1993 Mar-Apr; 34(2):151-156.

[11]. Brand A, Alves MC, Saraiva C, Loio P, Goulao J, Malta J, et al. Fetus in Fetu- Diagnostic criteria and differential diagnosis -A case report and literature review. J Ped Surg. 2004 April; 39(4):616-618.

[12]. Patankar T, Fatterpekar GM, Prasad S, Maniyar A, Mukherji SK: Fetus in fetu: CT appearance--report of two cases. Radiology 2000, 214:735-737.

[13]. Magnus KG, Millar AJ, Sinclair-Smith C C , Rode H: Intrahepatic fetus-in-fetu: a case report and review of the literature. J PediatricSurgery 1999, 34:1861-1864.

[14]. Aoki K, Matsumoto Y, Hamazaki M, Sano M, Fukumoto K, Fukaya T, Kuroda K, Tsutsumi R: MRI reveals fetus in fetu in the mediastinum. PediatricRadiology 2004, 34(12):1017-1019. 